\title{
The Effects of Effort and Trust on Board of Directors’ Performance
}

\author{
Bei Ye ${ }^{\text {a }}$ Johnny Jermias ${ }^{b^{*}}$ \\ ${ }^{a}$ College of Humanities, Law and Economics, Wuhan University of Science and Technology, \\ China \\ ${ }^{\mathrm{b}}$ Beedie School of Business, Simon Fraser University, Canada \\ *Corresponding author: Johnny Jermias, PhD,yeb323@hotmail.com; jjermias@sfu.ca
}

\begin{abstract}
This study investigates the effects of board effort and trust on board performance. Information acquisition and meeting behavior are used as proxies for board effort; cognitive conflict and trust are used to represent the degree of alignment between board and management. Based on a questionnaire survey of small and medium sized Chinese companies, we hypothesize and find that information acquisition and trust have a positive and significant impact on board's role performance; meeting preparation positively affects the strategic role, whereas meeting frequency has a positive effect on monitoring role of the board. The study provides meaningful insights for improving board effectiveness.
\end{abstract}

Key words: board behavior; effort; trust; governance; information; performance

\section{Introduction}

Effective corporate governance depends vitally on the role of the board of directors. Boards not only ratify managers' decisions and monitor their implementation, but also provide essential resources and secure those resources through linkages to the external environment. However by now we do not yet fully understand the factors contributing to the effectiveness of the boards.

Previous research has focused on the relations between board characteristics and corporate performance. ${ }^{1}$ The empirical findings by far have not reached an agreement, and sometimes are even contradictory. ${ }^{2}$ Therefore researchers have called for new directions in this field, and emphasized the need to closely study the behavioral aspects related to the processes and dynamics in and around the boardroom. ${ }^{3}$

In this respect, research in organization behavior, sociology and psychology could help a lot. In recent years occurred several theoretical models. However these models tend to propose an interlocked network of relationships that are hard to be empirically tested. ${ }^{4,5}$ Empirical study is faced with several obstacles. First, board behavior, unlike managerial actions, is hardly visible to the public. Disclosed data in companies' financial reporting could hardly tackle this problem. Second, relying on publicly available data, previous study tends to focus on big companies, lacking consideration for relatively small companies. Third, measurement of board effectiveness is controversial. Related literature often adopts financial performance as 
proxy for board performance, and neglects the complicated relationship between board function and corporate performance. In reality, the board is not directly responsible for a company's short term performance, and its major roles lie in ratifying management decisions, monitoring the implementation of those decisions, and counseling. An excellent board usually leads to robust development of the company's success in the long run, yet it does not necessarily bring about improvement in the short term financial performance.

Van Ees et al. proposed a simplified model about the effect of board behaviors on its effectiveness, with board characteristics as controls, and trust as a potential moderator. ${ }^{6} \mathrm{We}$ refer to their model and use effort, cognitive conflict, and trust as three major behavior variables to empirically test the associations between these variables and board performance. We collect data via a questionnaire survey among directors or executives of Chinese small or medium sized companies. On the whole, we find that board members' effort to acquire information has a significant positive impact on board effectiveness. Moreover, the trust between board and executives contribute positively to board effectiveness.

This study contributes to the existing literature in that: First, we modified the model proposed by Van Ees et al. and incorporated variables that are empirically testable. This modified model opens up opportunities for future research to investigate the impact of board behavior on board effectiveness as well as firm performance. Second, we use variables such as information acquisition and trust between boards and executives that are not publicly available and tend to be treated as unobservable variables by previous researchers. This helps open up the "black box" of board activities. Finally, with samples from small and medium size enterprises in China, our study fills the gap in the existing literature which mainly use data from large companies.

\section{Related Literature and Hypotheses Development}

\subsection{Related literature}

Board effectiveness refers to the extent to which the board fulfills its roles in corporate governance. According to Zahra and Pearce, the three generally accepted board roles are the control roles, the strategic roles and the service roles. ${ }^{7}$ The control roles concentrate on the control of agency problems and the promotion of firm efficiency in order to maintain high levels of shareholder value. The strategic roles have been recognized by proponents of the stewardship theory. Andrews states that a responsible and effective board should require of its management a unique and durable corporate strategy, review it periodically for its validity, use it as the reference point for all other board decisions, and share with management the risks associated with its adoption. ${ }^{8}$ The service roles are predominantly recognized by the resource dependence theory and the stakeholder theory, which include at least co-opting of external influencers, establishment of contacts, enhancement of the organization's reputation, and giving advice to organizations. ${ }^{9}$

Previous research tends to focus on relationships between board characteristics such as CEO 
duality, board size and board composition, and board effectiveness which is measured by accounting or market-based corporate performance. However, evidence is ambiguous and not conclusive. $^{10}$

As a result, in recent years more researchers have called for close study on board behavior. Several sets of theories have been developed such as the contingency theories, evolutionary theories, the board role theories, and the board process-related theories. According to the contingency theories, corporate governance designs need to consider the context and the actors. The evolutionary perspective is indicated through various learning loops at individual, group, organizational, and societal levels. As for the board process theories, Forbes and Milliken developed a theoretical model of board processes by integrating the literature on boards of directors with the literature on group dynamics and workgroup effectiveness. 4They argue that effectiveness of board role performance in terms of service and control roles results from interactions between board members, such as effort norms, use of knowledge, and cognitive conflict. They summarize various aspects of the board decision-making cultures, and use concepts like cognitive conflicts, cohesiveness, creativity, commitment, criticality, care, and consensus to describe the boards' decision-making culture.

Drawing from organizational behavior theory, Sharpe analyzes attributes of an effective board decision-making process, including forward-looking information, multiple information gathering channels, proactive goal setting and constructive conflict. ${ }^{11} \mathrm{He}$ emphasizes the importance of information acquired by the board of directors. He argues that multiple sources of information help to limit the CEO's biases and helps the board to identify a broader range of problems and opportunities, offer different viewpoints that reduce the CEO's reporting biases and improve the quality of analysis, and lead to more informed questioning of management's proposed responses and positions the board to offer realistic alternatives. Furthermore, he points out that information acquired by the board should be forward-looking and accurate, for it can help directors identify future problems or opportunities. The more accurate and strategic the information identified, the more robust the board's analyses.

Despite theoretical arguments, empirical studies for the above theories are scant. Although Forbes and Milliken's work created sizeable, structural models, they can hardly be tested since the required data cannot possibly be acquired with public databank or survey research targeted at top managers or directors.

Some researchers tried out on small scale interviews. Based on 40 in-depth interviews with company directors, Roberts, McNulty and Stiles found that a positive boardroom climate or decision-making culture is what matters most for creating accountability. ${ }^{12}$ They use words such as challenging, questioning, probing, discussing, testing, informing, debating, and encouraging to describe positive decision-making culture. Zona and Zattoni analyze boards of directors as workgroups and develop a model that relates group's social-psychological processes to three different board tasks: service, monitoring and networking. ${ }^{5}$ They test the model based on a survey on 301 large manufacturing firms in Italy, finding that process 
variables and, to a limited extent, demographic variables significantly influence board task performance. Furthermore, they find that board processes have a different impact on each specific board task and board task performance varies depending upon firm and industry characteristics.

Van Ees et al. propose a simplified conceptual model in which board communication and decision-making processes, such as effort norms, conflict and use of knowledge, influence board monitoring and strategic performance. ${ }^{6}$ In their model, board characteristics were treated as conditioning factors of board behavior, and trust between board and management was regarded as a moderator between board behavior and board role performance. They conducted a survey among 136 respondents at the board level in the Netherlands, and find that the use of knowledge positively and significantly influences the board monitoring role and strategic role performance. In addition, they find that cognitive conflict positively affects the board monitoring performance but negatively affects its strategy role. They also find that trust negatively moderates the relationship between use of knowledge and monitoring performance, which is contrary to their expectations. However, the moderating effect of trust between the other two behavioral factors and board effectiveness was not significant.

More scholars focus on observable board behavior as proxy for board effort. They believe that the number of board meetings is one of the important board attributes that can have significant influence on board monitoring effectiveness and firm value. ${ }^{13}$ Board meetings are seen as good opportunities for directors to coordinate and perform their tasks, where they can formally participate in monitoring management. ${ }^{14}$ Lipton and Lorsch argue that the more frequently directors meet, the more likely they could fulfill responsibilities. ${ }^{15}$ Byrne finds that if directors have too many positions elsewhere, they will hardly be able to attend board meetings regularly so as to carry out their duties. ${ }^{16}$ However, another stream of study puts forth that the role of board meeting may be over-valued. Jensen asserts that time for outside directors getting together is very limited, and is mostly consumed on communication among board members or between board and management. Besides, the schedule of board meetings are decided by CEOs, which is mainly about routine operation matters. Therefore, outside directors have little chance to execute their monitoring power. In his opinion, the board is usually inactive unless at times of crisis. ${ }^{17}$ As for empirical evidence, Lin et al. use the board attendance as a proxy measure of board supervisory quality and investigates the factors influencing board attendance, as well as their impact on firms' performance. ${ }^{18}$ The results show that higher board attendance enhances firm accounting performance, verifying that firms could view the attendance rate as an indication of the quality of the board supervision of these corporate monitors. Nikos empirically studied the relationship between board meeting frequency and corporate performance and finds a negative relationship between the two. ${ }^{19} \mathrm{He}$ argues that highly frequent meeting may be the board's passive reaction towards the downfall of corporate performance.

In short, in spite of abovementioned work, we do not yet fully understand how the board 
behavior influences the performance of the boards.

\subsection{Research model and hypotheses}

Based on Van Ees et al., we propose a simple research model which focuses on the effect of board effort and trust on its effectiveness, with board characteristics as control variables. We modify the model proposed by Van Ees et al. as follows:

First, board effectiveness is examined in three different dimensions, namely monitoring role, strategic role and service role, while Van Ees et al.'s studied the first two roles. Although in practice the strategic role and the service role both rely much on directors' professional experience and judgment, there are certain distinctions between the two. The strategic role involves long-term strategy formulation, business development, CEO nomination and even crisis responses, while the service role is mainly about providing counseling advice regarding administration, law, finance, technology, or marketing affairs.

The second difference is the choice of board behavior variables. We used "information acquisition" instead of "use of knowledge”. According to Van Ees et al., use of knowledge refers to the board's ability to tap the knowledge and skills available to it and then apply them to its activities. They emphasized the use of knowledge instead of the presence of knowledge. However this notion is very abstract for survey participants. Since the use of knowledge requires board members to actively acquire information related to their judgment, which is also more observable, we decided to use information acquisition to capture this behavior feature.

The third difference is about the role of trust. As the moderating effect in Van Ees et al.'s study was not significant in general, we chose to treat trust as an independent variable instead of a moderator.

Based on previous discussions, we developed the following hypotheses:

\subsubsection{Effort and board effectiveness}

Effort refers to the intensity of board members' resources directed towards governance roles. Given most board members have competing activities, their time dedicated to the company becomes very important. Only boards that promote high-effort behaviors among members are more likely to perform their monitoring, strategy and advising roles effectively.

However, board effort is difficult to measure. Existing literature often turns to proxy measures such as information acquisition and board meeting behavior. ${ }^{20}$

Information acquisition refers to how well the board takes an active part to acquire information they need to assist decision-making. Effective judgment and evaluation require adequate information input. However in reality, CEO almost always determines the agenda and the information flow to the board. As Jensen points out, serious information problems limit the effectiveness of board members in the typical large corporation. It severely hinders the ability of even highly talented board members to contribute effectively to the monitoring 
and evaluation of the CEO and the company's strategy. ${ }^{17}$ In spite of information disadvantage, the board may take measures to improve their information acquisition. Sharpe proposes forward looking information and multiple information gathering channels as prescriptions. ${ }^{11}$ In reality, board members should not confine themselves to passively waiting for information. Instead they may approach company employees, customers, suppliers or counseling firms for necessary information while making decisions or evaluations. The quality of information is also important for the board members to perform their tasks. The more accurate, timely and adequate the information, the more grounded the board's decisions will be, whether the decision involves monitoring, strategy or counseling. Hence the following hypothesis will be tested:

Hypothesis 1: Information acquisition is positively related to board monitoring, strategic and service role performance.

Previous studies have indicated that the more frequent a board meets, or the more members attend meetings, the more efforts are exerted. For example, using seven years COMPUSTAT and EXECUCOMP data from 1999 to 2005, Brick and Chidambaran found that both board meeting frequency and attendance are positively related to firm performance. ${ }^{21}$ In a similar vein, Chou et al. examines the relation between board meeting attendance and performance. ${ }^{22}$ Using a sample of Taiwanese listed corporations, they found that the director's meeting attendance is positively associated with firm performance. Similar results were reported by Liang et al. ${ }^{23}$ Using a sample of 50 largest Chinese banks during the period of 2003-2010, they reported that the frequency of board meeting and director's attendance positively affect firm value. Hence we have the following hypotheses to be tested:

Hypothesis 2: Board meeting frequency is positively related to board monitoring, strategic and service role performance.

Hypothesis 3: Board meeting attendance ratio is positively related to board monitoring, strategic and service role performance.

One of the main activities of board members is to engage in boardroom debates. Scarpati argues that board members are required to review financial statements, independent accountant communications, internal audit reports, management reports and correspondence. ${ }^{24}$ These activities take place before the meeting and require considerable preparation time. Board members are expected to arrive at the board meeting prepared to address key issues and ask management the right questions to ensure that management take actions that are beneficial to the shareholders. Therefore, the following hypothesis will be tested:

Hypothesis 4: Directors' preparation for meeting is positively related to board monitoring, strategic and service role performance.

\subsubsection{Cognitive conflict and board effectiveness}

Cognitive conflict refers to the disagreement among group members, which arises from their 
independent information-processing and judgment. In group decision-making conflict is both expected and appreciated. Janis points out that critical thinking can be instrumental in breaking through too much cohesiveness and groupthink in the boards. ${ }^{25}$ It helps board members identify questions that diverge from standard operating procedure, thus helps to overcome structural biases that lead to pro forma approvals. Although conflict is often considered as a negative aspect of group dynamics, it can be very important for members of a group to function well. Jehn asserts that a cognitive conflict arises from disagreement between group members about the content of the tasks to be performed because of differences in viewpoints, ideas, and opinions. ${ }^{26} \mathrm{He}$ argues that cognitive conflicts are important ingredients for effective group task performance since they increase group members' understanding of the issues being debated and enable the members to critically evaluate their tasks and ideas. Cognitive conflicts also improve group decisions since these conflicts mitigate the tendency of group members to engage in confirmatory biases when making group decisions. Simons and Peterson argue that cognitive conflicts facilitate group members to express their own perspectives on the tasks to be performed and hence have a positive impact on task commitment and member satisfaction. ${ }^{27}$ Previous studies found that cognitive conflicts have stronger positive impacts on decision making in non-routine tasks and also tasks performed at higher level of organizational hierarchy. ${ }^{28}$ Since board members typically engage in non-routine tasks at the high level of organizational hierarchy, we propose that cognitive conflicts will have a positive effect on board performance. Therefore, we will test the following hypothesis:

Hypothesis 5: Cognitive conflict in boardrooms is positively related to board monitoring, strategic and service role performance.

\subsubsection{Trust and board effectiveness}

The role of trust has long been recognized in social psychology. Trust is defined as a belief in the reliability, truthfulness or ability of someone. Trust plays an important role in supporting confidence-building and acting as an enabler to develop synergy among group members. Huse believes that trust between board members and top management is a prime condition for board members to function effectively. ${ }^{3}$ Westphal suggests that the trust between board of directors and management help executives to engage less in impression management and to seek greater input from the board. ${ }^{29}$ Likewise, board members will be more willing to offer meaningful suggestions and candid feedback knowing that management will consider their views. Hence, Sundaramurthy and Lewis suggest that board's effectiveness depend on the trust between the board and the management. ${ }^{30_{30}}$ With higher levels of trust, management will be more willing and confident to share information and knowledge with the board, which will facilitate board monitoring and strategic counseling. At the same time, higher trust means the board's opinions will be more easily conveyed, understood or carried out, leading to better efficiency of board governance. Finkelstein and D'Aveni suggest that trust between board and 
executives provides a unity of command that will reduce role conflict and help shareholders understand the unity of decision making authority. ${ }^{31}$ Therefore the following hypothesis will be:

Hypothesis 6: Trust is positively related to board role performance.

\section{Data and method}

\subsection{Sample and data collection}

We designed an investigation questionnaire regarding board characteristics, board behavior and governance effectiveness. Board characteristics include board size, ratio of outside directors, expertise composition and so on. As for board behavior, we mainly investigated board meeting behavior (including meeting frequency, attendance ratio and meeting preparation), group discussion manner and decision-making process, information acquisition channels and information quality, and trust between board and management. As for board governance effectiveness, we invited the respondents to make evaluation on board governance effectiveness in terms of monitoring, strategy and counseling roles. For all the subjective questions abovementioned, the respondents made evaluations using a five-point Lykert scale system.

According to the Company Law of China, all joint stock limited companies must set up boards of directors, whereas there is no such mandatory rule for limited liability companies. Therefore we confine the investigation to board members, secretaries or executives of joint stock limited companies. The investigation was undertaken on-line, and the number of informants was limited to one for each company to avoid repetition. During the one-month survey, 380 questionnaires were sent out, with 313 of them returned on time. By means of manual inspection, 105 questionnaires were deleted because of incomplete answers or obvious errors, leaving 208 usable responses. Manual review shows there are no repetitive IP addresses or company names among the 208 samples, and the geographic distribution is reasonably scattered, covering all major economic zones in East, Middle and West China.

The administrative roles of the respondents are diverse, with the distribution in percentage as follows: director or secretary, 48\%; CEO or Deputy President, 28\%; chairman or vice chairman, 15\%; other executives, 9\%. We compared average questionnaire scores of each administrative group, and did not find any significant variances from the total sample with variance ranging from $-0.71 \%$ to $2.41 \%$.

Sample companies are mainly privately controlled (54\%), followed by government controlled (25\%), foreign controlled (11\%) and collectively owned (10\%). The maximum employment size of the sample companies is 33000, whereas the minimum is 52, with an average of 1890 . Compared with most empirical literature in China, this sample mostly comprises of small or medium sized companies. As board behavior is a sensitive and debated topic, anonymity was guaranteed to the respondents in advance. 


\subsection{Variable measurement}

Definitions of the variables are shown in Table 1.

There are three dependent variables representing board effectiveness: effective monitoring EFFMON, effective strategy EFFSTR, and effective service EFFSER. We use a multi-item scale approach to measure the dependent variables.

Table 1- Variables and definitions

\begin{tabular}{|c|c|c|}
\hline Category & Variable & Definition \\
\hline \multirow{3}{*}{$\begin{array}{l}\text { Effectiveness } \\
\text { (Dependent } \\
\text { variable) }\end{array}$} & EFFMON & Effectiveness in terms of monitoring role based on respondents' assessment. \\
\hline & EFFSTR & Effectiveness in terms of strategy role based on respondents' assessment. \\
\hline & EFFSER & $\begin{array}{l}\text { Effectiveness in terms of providing counseling service based on respondents' } \\
\text { assessment. }\end{array}$ \\
\hline Information & INFOR & $\begin{array}{l}\text { Information acquisition condition by considering three information sources, } \\
\text { namely management source, informal internal source and external source. } \\
=\text { [board-management communication +internal source } \\
\text { frequency*quality/5+external source frequency*quality/5]/3 }\end{array}$ \\
\hline \multirow[t]{3}{*}{ Meeting } & MEETFREQ & Board meeting frequency in the past year. \\
\hline & MEETATTD & Board meeting attendance ratio (\%) in the past year. \\
\hline & MEETPREP & $\begin{array}{l}\text { Directors' board meeting preparation sufficiency based on subjective } \\
\text { evaluation by respondents. }\end{array}$ \\
\hline $\begin{array}{l}\text { Cognitive } \\
\text { conflict }\end{array}$ & CONFLICT & $\begin{array}{l}\text { Willingness and freedom of expressing different opinions based on } \\
\text { respondents' assessment. }\end{array}$ \\
\hline Trust & TRUST & Trust between board and management based on respondents’ assessment. \\
\hline Characteristics & BSIZE & Number of directors in the board. \\
\hline
\end{tabular}

The explanatory variables consist of information acquisition, board meeting (meeting frequency, attendance and preparation), cognitive conflict, and trust. Information acquisition represents board' effort to gather information through communication with management, internal and external channels and to ensure that information is timely and accurate. Cognitive conflict represents the directors' willingness and freedom to express different opinions. Trust represents the level of trust between board members and management. We included board size as a control variable since this variable has been shown in previous studies to affect board performance. Respondents were asked to indicate their evaluation on a 5-point Likert-type scale ( 1 = very weak; and 5 = very strong).

The variables were quantified in different ways. For objective measures with one item scale such as board size, meeting frequency, attendance ratio and meeting preparation, we adopted the respondents' answers as the variable value. For variables with multi-item scale such as effectiveness and trust, the value is based on the average of responses to a group of questions in each category. As information acquisition involves both frequency and quality, we use the formula in Table 1 to calculate its value.

\footnotetext{
(1) For limited space, the scale items are not included here, but are available upon request.
} 


\section{Statistical analyses and results}

\subsection{Descriptive and correlations}

Descriptive statistics and correlation coefficients are displayed in Table 2.

The monitoring, strategic and service roles positively correlate with each other significantly, and the correlation is high between the strategic role and service role. Since strategic role and service role of the board both require professional knowledge and experience of the directors, the high correlation between the two is reasonable and easily understood.

Table 2-Descriptive and Correlations

\begin{tabular}{|l|l|l|l|l|l|l|l|l|l|l|l|l|l|}
\hline & $\mathrm{N}$ & Mean & SD & 1 & 2 & 3 & 4 & 5 & 6 & 7 & 8 & 9 & 10 \\
\hline 1EFFMON & 208 & 4.183 & 0.484 & 1 & & & & & & & & & \\
\hline 2EFFSTR & 208 & 4.266 & 0.427 & $.474^{* * *}$ & 1 & & & & & & & & \\
\hline 3EFFSER & 208 & 4.202 & 0.379 & $.588^{* * *}$ & $.727^{* * *}$ & 1 & & & & & & & \\
\hline 4INFOR & 208 & 3.786 & 0.599 & $.450^{* * *}$ & $.512^{* * *}$ & $.579^{* * *}$ & 1 & & & & & & \\
\hline 5MEETFREQ & 208 & 6.601 & 4.514 & $.137^{* *}$ & .114 & .096 & .078 & 1 & & & & & \\
\hline 6MEETATTD & 208 & 91.019 & 8.731 & .025 & -.114 & -.013 & .000 & $-.157^{* *}$ & 1 & & & & \\
\hline 7MEETPREP & 208 & 4.490 & 0.573 & .067 & $.200^{* * *}$ & $.197^{* * *} .142^{* *}$ & .097 & -.063 & 1 & & & \\
\hline 8CONFLICT & 208 & 4.067 & 0.777 & $.166^{* *}$ & .080 & .107 & $.305^{* * *} .055$ & .039 & .045 & 1 & & \\
\hline 9BSIZE & 208 & 9.563 & 3.206 & .052 & .099 & .127 & .111 & .063 & -.107 & .061 & .049 & 1 & \\
\hline 10TRUST & 208 & 4.246 & 0.366 & $.388^{* *}$ & $.562^{* * *}$ & $.631^{* * * *} .454^{* * *} .029$ & -.094 & .071 & .125 & .083 & 1 \\
\hline
\end{tabular}

$* *$, and $* * *$ denote the significant level of 0.05 , and 0.01 respectively, based on two-tailed tests.

There are significantly positive correlations between INFOR, TRUST and all board performance measures. In terms of meeting behavior, there are positive and significant correlations between meeting preparation and board strategic and service roles. However, correlation between meeting frequency and board performance is not significant, except for monitoring role which is positive and significant. Finally, there is a positive correlation between conflict measure and board monitoring performance.

Among the group of meeting measures, there is a negative and significant correlation between meeting frequency and meeting attendance. It sounds reasonable considering the time allocation of directors is competitive after all. The correlation coefficients between each pair of independent variables are all very low, with the highest absolute value of 0.454 . Thus there should not be serious problem of multicollinearity.

\subsection{Regression analysis}

Multivariate linear regressions were run via SPSS 20, and the results are shown in Table 3.

The dependent variables are board's effectiveness in terms of monitoring, strategy and counseling service. 
Model 1 indicates that information acquisition and trust are positively and significantly related to the monitoring role, which supports Hypothesis 1 and Hypothesis 6. The relation between meeting frequency and monitoring role is positively and marginally significant. This provides some support for Hypothesis 2. Coefficients for other meeting behavior variables and conflict variable are not statistically significant.

Regressions on Model 2 and Model 3 yield similar results. Model 2 shows that information acquisition and trust are positively and significantly related to the strategic role of the boards. Model 3 of Table 3 reveals that information acquisition and trust are both positively and significantly related to the service role of the boards. However unlike in Model 1, meeting preparation shows a positive effect on the strategic role and the service role, while meeting frequency seems to have little effect on board performance. Therefore both regressions provide support for Hypothesis 1, Hypothesis 4, and Hypothesis 6. The regressions did not find evidence supporting the other hypotheses. Comparatively speaking, Model 2 and Model 3 have a better fit as indicated by the higher adjusted R-square, which suggests that the strategic or service role of the board are better explained than the monitoring role by the variables we have considered.

Table 3- Regression results of board effectiveness

\begin{tabular}{|l|l|l|l|}
\hline & EFFMON & EFFSTR & EFFSER \\
\hline & $($ Model 1) & (Model 2) & (Model 3) \\
\hline Constant & $1.390^{* *}$ & $1.301^{* * *}$ & $.765^{* *}$ \\
\hline INFOR & $.262^{* * *}$ & $.233^{* * *}$ & $.230^{* * *}$ \\
\hline MEETFREQ & $.012^{*}$ & .006 & .004 \\
\hline MEETATTD & .004 & -.003 & .002 \\
\hline MEETPREP & -.004 & $.091^{* *}$ & $.078^{* *}$ \\
\hline CONFLICT & .018 & -.043 & -.037 \\
\hline BSIZE & -.001 & .004 & .007 \\
\hline TRUST & $.318^{* * *}$ & $.473^{* * *}$ & $.482^{* * *}$ \\
\hline $\mathrm{N}$ & 208 & 208 & 208 \\
\hline $\mathrm{F}$ & $10.059 * * *$ & $21.445^{* * *}$ & $32.364 * * *$ \\
\hline Adjusted $\mathrm{R}^{2}$ & .235 & .409 & .515 \\
\hline
\end{tabular}

$*, * *$, and $* * *$ denote the significant level of $0.10,0.05$, and 0.01 respectively based on two-tailed tests.

Overall, we find that among various aspects of board effort, information acquisition always contributes significantly to board role performance, which is in line with our Hypothesis 1. This suggests that information acquisition behavior is a key element in board effectiveness. Enriching information sources and enhancing information quality will help improve board decision-making.

The relationship between meeting behavior and board effectiveness is not consistent. The major functioning factor seems to be meeting preparation. It positively and significantly 
affects board strategic role and service role. However, it has a weak effect on board monitoring role. One plausible explanation to this weak result is that the model we use in this study might overlook some unknown explanatory factors, since the monitoring model has a much lower fit than the other two models. The results indicate that meeting frequency and meeting attendance do not have significant impacts on board performance, except that meeting frequency have a marginal positive effect on board monitoring role.

The variable TRUST are always positively and significantly related to all the board governance roles, which is in line with the notion that trust relationships can improve the effects of board processes on board performance. ${ }^{12}$ When there is a high level of trust, the board of directors will believe in the knowledge and experience of the management team. The management will turn to the board for advice whenever necessary and the latter will be pleased to offer their opinion. The board will be willing to authorize management to act as its spokesman, and directors would like to exchange ideas with management. In the context of corporate governance, trust reduces frictions during communications between management and board. Moreover, based on high level of trust, we expect information provided by management will be more objective and complete, which in turn will facilitate effective boards' decision-making.

As for cognitive conflict, our study does not find evidence supporting its positive role. One possible reason is that in reality it is very difficult to tell the difference between cognitive conflict (rational and based on different judgment) and emotional conflict (which is usually irrational). Since our measure of cognitive conflict was based on respondents' estimation about directors' freedom and willingness to express different opinions, their observation may have mingled emotional conflicts which might mitigate the positive effects of cognitive conflicts. As for the control variable, board size does not show any significant relationship with board role performance in the three models.

The F-tests for the above three regression models are all highly significant. We conducted multicollinearity tests via SPSS 20, which show the VIFs for all seven independent variables are less than 1.5. Since correlation between independent variables are all very low (with the absolute values less than 0.46 ), there should be no serious problem of multicollinearity. ${ }^{1}$

For robustness check, we then tried deleting insignificant variables such as MEETATTD, CONFLICT, and BSIZE and ran backward regressions. The results were consistent with the above regressions. In addition to models mentioned above, we also tried testing the moderating effects proposed by Van Ees et al. However the regression results did not show significant moderating effects of TRUST on the relation between board characteristics and board effectiveness. ${ }^{2}$

\footnotetext{
(1) Multi-collinearity may not affect the least squares estimates of the regression coefficients when the VIF is smaller than 10 (Dielman, 2001).

(2) For limited space, the above results were not reported here, but are available upon request.
} 


\section{Conclusions}

As an attempt to reveal the relevance of board behavior, this study tried to probe board working process via a questionnaire survey, and empirically explore the potential relationships between board behavior and its governance effects. The study yielded some interesting findings.

First, as expected, we found information acquisition plays an important role in the process. How boards gather information and the quality of the information they acquire have a significant effect upon the monitoring, strategic and service role performance. The more information sources there are, and the more reliable the information is, the more well-grounded board's evaluation, discussion and decision-making will be. This finding underpins the importance for boards to search for independent information from multiple sources instead of waiting passively for managerial report.

Second, the research shows that trust has a significant positive effect on all of the board roles. Trust may facilitate the sharing of information between management and board, thus increase efficiency of board functioning. However in our study we did not witness significant moderating effect by trust as proposed by Van Ees et al.

Third, among the three measures of meeting behavior, namely meeting frequency, meeting attendance and meeting preparation, the last one is the most related to board efficacy, especially to board strategic role and service role. The results suggest that good meeting preparation contributes to board governance, which is in line with practitioners' experience that it is important to provide a productive meeting agenda, relevant background information, in advance notice, and most important, directors should do their homework as well as possible. Our study did not find evidence of significant relationships between meeting frequency or meeting attendance and the board governance roles, except that meeting frequency shows a less significant, positive effect on board monitoring role. As Jensen pointed out, board meetings are probably reactive, rather than proactive. Therefore meeting frequency or attendance may hardly be an explanatory factor of board governance.

Unlike Van Ees et al.'s study, our research did not find significant relationship between cognitive conflict and board role performance, which is not consistent with our expectation. We wonder if it results from inappropriate measure of cognitive conflict in our questionnaire. In short, the study partly confirms the relevance of board process variables to board performance as suggested by Forbes and Milliken. Especially it underpins the importance of information acquisition during board working process and trust between board and management. These findings provide meaningful inspirations for future improvement of board governance. Besides, as far as we know, our study is among the first to provide evidence from relatively small companies in China. Thus the findings may as well enrich existing literature about board behavior and governance effectiveness.

The findings are subject to some limitations. First, data are mainly based on subjective 
questionnaire responses, which may be affected by respondents' thinking habits. Second, data used were cross-sectional, which made it difficult to provide causal interpretations. Finally, the insignificant effect of cognitive conflict suggests we might need better measures to depict cognitive conflict. For future study we suggest improvement in the abovementioned aspects, and bring in more empirical tests on various types of companies.

\section{Acknowledgements}

The study is supported by the National Social Science Fund of China (No. 12BGL047). Both authors contribute equally to the paper. We thank the sample companies and their representatives for the generosity to provide data used in this study.

\section{References}

1. L. Gani, J. Jermias, Investigating the effect of board independence on performance across different strategies, International Journal of Accounting. 42 (2006) 295-314.

2. W. Li, J. Niu, X. Song, Theoretical origin and clues in board governance research, Nankai Management Review. 12 (2009) 130-145.

3. M. Huse, Accountability and creating accountability: a framework for exploring behavioral perspectives of corporate governance, British Journal of Management. 16 (2005) 65-79.

4. D. P. Forbes, F. J. Milliken, Cognition and corporate governance: understanding boards of directors as strategic decision-making groups, Academy of Management Review. 24 (1999) 489-505.

5. F. Zona, A. Zattoni, Beyond the black box of demography: board processes and task effectiveness within Italian firms, Corporate Governance: An International Review. 15(2007) 852-864.

6. H. Van Ees, G.Van der Laan, Theo J. B. M. Postma, Effective board behavior in the Netherlands, European Management Journal. 26 (2008) 84-93.

7. S. A. Zahra, J. A. Pearce, Boards of directors and corporate financial performance: a review and integrative model, Journal of Management 15 (1989) 291-334.

8. K. R. Andrews, Director's responsibility for corporate strategy, Harvard Business Review. 58 (1980) 30.

9. H. Mintzberg, Power in and around Organizations. Prentice-Hall, NJ, 1983, 81-86.

10. B. E. Hermalin, M. S. Weisbach, Boards of directors as an endogenously determined institution: a survey of the economic literature, Economic Policy Review. 9(2003) 7-26.

11. N. F. Sharpe, Questioning authority: the critical link between board power and process, Journal of Corporation Law. 38 (2012) 1-51.

12. J. Roberts, T. McNulty, P. Stiles, Beyond agency conceptions of the work of the 
non-executive director: creating accountability in the boardroom, British Journal of Management. 16 (2005) S5-S26.

13. J. Conger, D. Finegold, E. Lawler III, Appraising boardroom performance, Harvard Business Review. 76 (1998) 136-148.

14. P. Jiraporn, W. N. Davidson III, P. Dadalt, Y. Ning, Too busy to show up? An analysis of directors' absences, Quarterly Review of Economics and Finance. 49 (2009) 1159-1171.

15. M. Lipton, J. W. Lorsch, A modest proposal for improved corporate governance, Business Lawyer. 48 (1992) 59-77.

16. J. Byrne, Listen up: the national association of corporate directors' new guidelines won't tolerate inattentive, passive, uninformed board members, Business Week. 25 (1996) 256-279.

17. M. Jensen, Modern industrial revolution, exit, and the failure of internal control system, Journal of Finance. 48(1993) 831-880.

18. Y. Lin, Y. M. Chou Yeh, F. Yang, Supervisory quality of board and firm performance: a perspective of board meeting attendance, Total Quality Management \& Business Excellence. 25 (2014) 264-279.

19. V. Nikos, Board meeting frequency and firm performance, Journal of Financial Economics. 53 (1999) 113-142.

20. A. Omri, Multiple directorships and board meeting frequency, Applied Financial Economics. 24 (2014) 983-992.

21. I. E. Brick, N. K. Chidambaran, Board meetings, committee structure, and firm value, Journal of Corporate Finance. 16 (2010) 533-553.

22. H.I. Chou, H. Chung, X. Yin, Attendance of board meetings and company performance: evidence from Taiwan, Journal of Banking and Finance.37 (2013) 4157-4171.

23. Q. Liang, P. Xu, P. Jiraporn, Board characteristics and Chinese bank performance, Journal of Banking and Finance. 37 (2013) 2953-2968.

24. S.A. Scarpati, CPAs as audit committee. Journal of Accountancy. September (2003) 32-35.

25. I. L. Janis, Victims of groupthink: a psychological study of foreign policy decision and fiascoes, Houghton Mifflin, Boston, 1972, 19-51; 209-215.

26. K. Jehn, A multimethod examination of the benefits and detriments of intragroup conflict, Administrative Science Quarterly. 40 (1995) 256-82.

27. T. L. Simons, R. S. Peterson, Task conflict and relationship conflict in top management teams: the pivotal role of intragroup trust, Journal of Applied Psychology. 85 (2000) 102-11. 
28. T.A. O'Neill, N. J. Allen, S. E. Hastings, Examining the "pros"and “cons" of team conflict: a team-level meta-analysis of task, relationship and process conflict, Human Performance. 26 (2013) 236-260.

29. J.D. Westphal, Collaboration in the boardroom: behavioral and performance consequences of CEO-board social ties, Academy of Management journal. 42 (1999) 7-24.

30.C.Sundramurthy, M. Lewis, Control and collaboration: paradoxes of governance. Academy of Management Review. 28 (2003) 397-415.

31. S. Finkelstein, R. A. D'Aveni, CEO duality as a double-edged sword: how boards of directors balance entrenchment avoidance and unity of command, Academy of Management Journal. 37 (1994) 1079-1108. 